\title{
A Four-in-one Teaching Model for Fundamental Nursing Based on UCD Theory
}

\author{
https://doi.org/10.3991/ijet.v15i15.15713 \\ Pan $\mathrm{Li}\left({ }^{\bowtie}\right)$, Chunyan Li \\ School of Nursing, Xiangnan University, Chenzhou, China \\ pp18075531160@163.com
}

\begin{abstract}
With the change of health concept and medical mode, the nursing personnel in the 21 st century will confront day by day expanding work domain, and new opportunities and challenges put forward new requirements for the scale and quality of nursing personnel training. The core problem of nursing education reform is course reform. At present, nursing specialty teaching has such problems as the lack of learning initiative and imperfect course evaluation system which seriously affect the teaching effect. Hence, this study applied UCD theory, summarized the principles of multimedia teaching design based on UCD theory, and applied it in network course design of nursing teaching. The detailed design application method expanded in detail from three aspects: course process, course content and course experience. Meanwhile, four-in-one (blended-flipped-autonomous-collaborative) teaching model was proposed. The teaching model is based on the functional structure relation between course objective and course implementation process, and element analysis model of course quality process. The course quality evaluation index system oriented to objective-process was constructed from six dimensions (including course objective adaptation, teaching resource guarantee, teaching program execution, teaching program suitability, quality assurance effectiveness and course objective attainment) to assess the application effect of four-in-one teaching model in Fundamental Nursing. The results show that the four-in-one teaching model better improves students' self-management ability, information acquisition ability, learning and cooperation ability, compared with traditional teaching models. Objective-process course quality evaluation index system can quantify evaluation of teaching effect from multiple dimensions and make teachers optimize course design with pertinence.
\end{abstract}

Keywords-Four-in-one; UCD theory; objective-process; nursing

\section{$1 \quad$ Introduction}

The rapid development of multimedia information technology brings new hopes and challenges to medicine course teaching. More and more teachers and students can contact learning resources with pictures, texts, sound and images via internet information technology. Meanwhile, they can directly learn and exchange in classroom and after class without time and place restrictions. But the fact proves that 
the technology itself cannot help learning, and the key is to integrate it into daily classroom teaching and make it a tool and purpose of active thinking and actions together with classroom textbook teaching, thus cultivating students' ability to practice and apply information for new knowledge construction. Some problems still exist in teaching the course of Fundamental Nursing, such as disconnection between nursing teaching and clinical application, insufficient professional quality education, lack of protection awareness education, and disjunction of teaching method and assessment method with the era [1]. These problems seriously affect the teaching effect of Fundamental Nursing.

Nursing personnel are technical personnel in short supply in the four major industries. How to accelerate the cultivation of nursing personnel who adapt to the society, market, industry and future is a topic to be solved urgently by nursing education workers and managers. Fundamental Nursing covers basic nursing theory, elementary knowledge and skills which must be mastered by clinical nursing workers, and it is the foundation for learning specific nursing and also the core course of nursing personnel training [2]. Thus, teaching reform of this course is a focus of relevant educators. In view of this, this study started from college nursing personnel training and combined UCD theory to change the teaching from four aspects: teaching idea innovation, teaching mode innovation, innovation of teaching evaluation mode, and innovation of course quality evaluation. Besides, the teaching mode was applied in the teaching practice of Fundamental Nursing, in the hope of providing a new teaching reform thought and reference for medical education.

\section{State of the Art}

With the rapid development of internet, multimedia technology starts to be deeply applied in course teaching and becomes a key mode of modern teaching. The combination of multimedia technology and new teaching models has become a mainstream means in current teaching. How to scientifically apply new teaching models to stimulate students' learning initiative, expand teaching content and improve teaching efficiency is a common concern at present. Nursing education has strong international universality and comparability. It is found from literature search that, nursing multimedia teaching develops rapidly in many economically developed countries, and their nursing multimedia education system, evaluation system and course setting are characteristic and in an internationally leading position. For example, multiple innovative teaching modes have been developed and practiced in multimedia teaching courses, including Team-based Learning (TBL) [3], Problembased Learning (PBL) and Case-based Learning (CBL). In addition, some valuable teaching experience has been accumulated. TBL, PBL and CBL teaching models are implemented in Harvard Business School, and they have aroused extensive attention of the academic circle and educational circle. They have been applied in multidisciplinary fields like medicine, law and commercial science. There is also relatively mature application experience in nursing specialty teaching. Feng [6] applied a multimedia teaching strategy which was developed by three faculty integrating case 
study, questioning and animation of skills and pathophysiology in the class of infection control at an urban university in the Midwest United States, and found that animation multimedia technology could enhance learning initiative of nursing majors. Li et al. [7] designed the learning framework of a Mobile Education (FRAME) model for nursing major at the University of Hong Kong and found that mobile technology improved the portability and accessibility of learning information, and networking tools promoted interaction among students and between students and the teacher. Wang [8] discovered that the students of nursing major tended to entertainmentrelated multimedia teaching equipment, and teacher's application of teaching innovation equipment presented significant positive correlation with students' academic performance.

In recent years, nursing multimedia teaching has developed in the aspects of personnel training, scientific research and nursing service level, and also gradually become a focus of educators. For the problem of multimedia teaching application in nursing major, some research indicates that the blended teaching model which is deeply combined with internet has some defects in nursing specialty teaching, including teacher's lack of relevant theoretical basis, poor online teaching skills and insufficient interaction between teachers and students, etc. $\mathrm{Wu}$ proposed the application of TBL+PBL+CBL blended teaching. Such blended teaching model encourages teamwork, advocates problem orientation and pays attention to case discussion and application. Meanwhile, the results of questionnaire survey show that students' class attendance rate, personal exhibition performance, teamwork performance and final result under TBL+PBL+CBL blended teaching are obviously superior to traditional teaching model [9].

In conclusion, existing studies have gained certain development in innovative teaching models such as blended teaching, collaborative teaching, autonomous teaching and flipped classroom teaching $[10,11]$. It is found that current nursing courses usually have the following teaching characteristics: students have urgent demand for specialized knowledge; the number of students is large; students have high requirements for teacher's innovation and expertise. Hence, existing multimedia teaching introduces learner-based design thinking in the design process to meet students' knowledge demand, help students master knowledge and improve user experience. However, it can be found through relevant document analysis that, both the developers and teachers consider students' needs. But, the function modules of multimedia teaching mostly have single-point function, and there is no correlation between each other. Developers lack systematic and all-round theoretical guideline in the design process, and add scattered teaching services through the research of students' current situations. The design of multimedia teaching system with such method will bring about blind zone of experience, and cannot overall capture students' demand for nursing course content and experience, thus affecting students' learning efficiency and learning initiative. Based on this, "four-in-one" teaching model based on UCD theory was constructed in this study. The innovations exist in the following four aspects: firstly, innovate for teaching idea and achieve "four changes". The teaching idea changes to student orientation from teacher orientation. Teaching space changes to online teaching from classroom teaching. Teaching 
content changes to general \& professional education from professional education. Teaching evaluation changes to process evaluation from outcome assessment. Secondly, innovate for teaching model and achieve four-dimension integrated learning: in campus and in classroom, in campus and outside classroom, outside campus and in classroom, outside campus and outside classroom. Thirdly, innovate for evaluation method, and achieve online teaching evaluation, satisfaction evaluation, learning analysis system and online \& offline evaluation. Fourthly, innovate for course quality evaluation, and start from teaching objective and teaching process to construct objective-process teaching quality evaluation system. Based on this, this study expects to guide nursing teaching course through UCD theory, integrate the above four new teaching models, further standardize and improve multimedia teaching of nursing.

\section{3 "Four-in-one" teaching model based on UCD Theory}

\subsection{Integration of UCD theory in nursing teaching}

UCD (User-Centered Design) initially came from "user-centered" design philosophy, i.e. "people-oriented" design philosophy. Such concept analyzes user demand, ability and behavioral pattern first, and then meets people's demand, ability and behavioral pattern through the design. Then, UCD theory is continuously applied and practiced in many fields such as architecture, industrial design, interactive design, ergonomics, and distance education. According to the design method of UCD theory, this study integrated teaching characteristics of nursing major and concluded the methods of nursing major teaching design based on UCD theory (as shown in Fig.1).

Concern and humanity: Concern and humanity mean UCD-based design method lays emphasis on user experience and scientific and rational course serves are designed for users. Even the learners with different professional level can participate in straightaway learning activities.

Intuition and foreseeability: Intuition and foreseeability mean UCD theory can let learners know course results in time, practically experience their knowledge output ability and stimulate their learning initiative.

Scientificity and standardization: Scientificity and standardization mean UCDbased course development should conform to standard and scientific course design method so that course content more complies with user demand, and the course design method based on teacher's teaching experience is changed.

Correction, completeness and progress: Correction, completeness and progress mean this design method is based on rich knowledge points and core points of nursing major teaching content, and combines UCD theory so that the teaching system of nursing major is in the process of continuous optimization and improvement. 


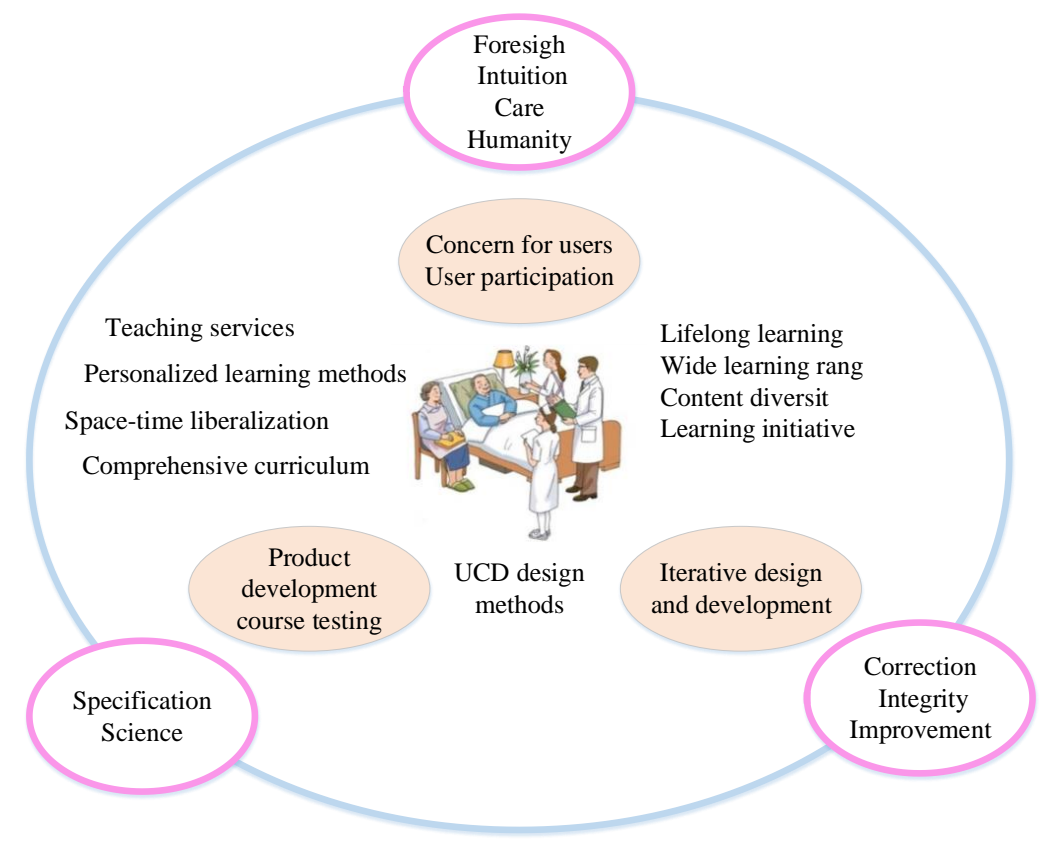

Fig. 1. Design method of nursing major teaching system based on UCD theory

\subsection{Application of four-in-one teaching mode integrated with UCD theory in nursing Course}

The teaching process of nursing major was designed according to concern, intuition, scientificity and correction in the teaching system design method of nursing major. Finally, the design process of nursing network course based on UCD theory was gained, as shown in Fig.2.

"Four-in-one" teaching model means theoretical knowledge explanation, case analysis, scenario simulation and practical learning are combined in nursing major teaching process.[6] Firstly, theoretical knowledge explanation. When the teacher explains theoretical knowledge of nursing, the main concepts should be stressed to ensure key knowledge points can be learned in classroom. Students can lay a solid foundation for later teaching process through theoretical knowledge learning, secondly, case analysis. Case-based teaching trains students' ability to solve practical problems, independent thinking ability and language expression capacity, which conforms to the requirements of quality-oriented education idea. Thirdly, scenario simulation teaching. Scenario simulation teaching is based on situational dialogue and role play. 


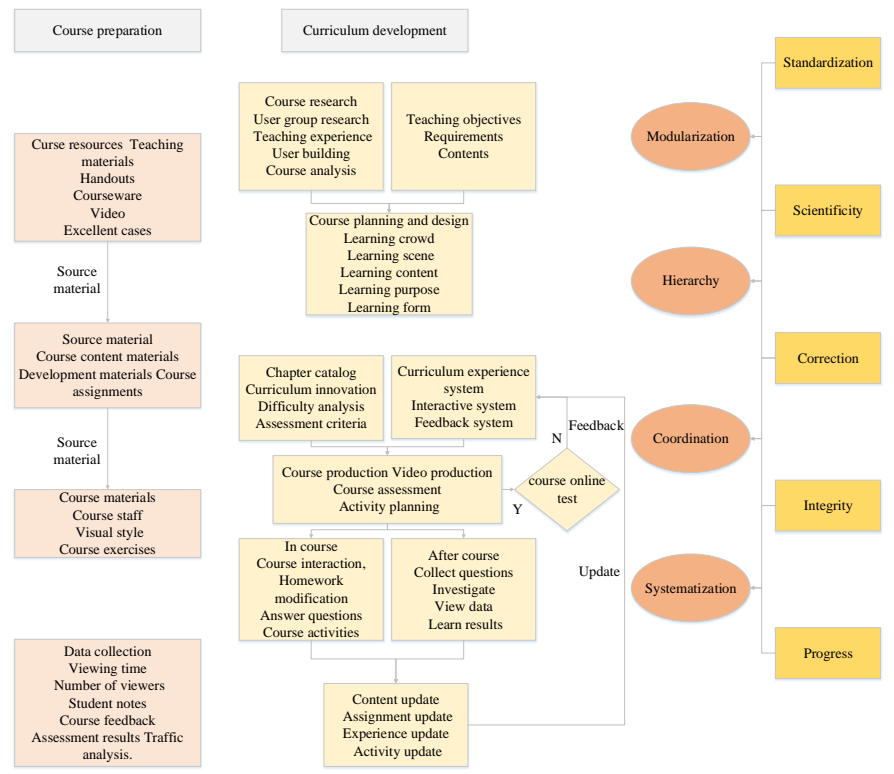

Fig. 2. Design process of nursing network course based on UCD theory

In this teaching model, the teacher and students can fully exchange and communicate, which can mobilizes students' learning initiative to a maximum extent. Fourthly, practice. This can be achieved through setting up the teaching model of combining colleges and enterprises.

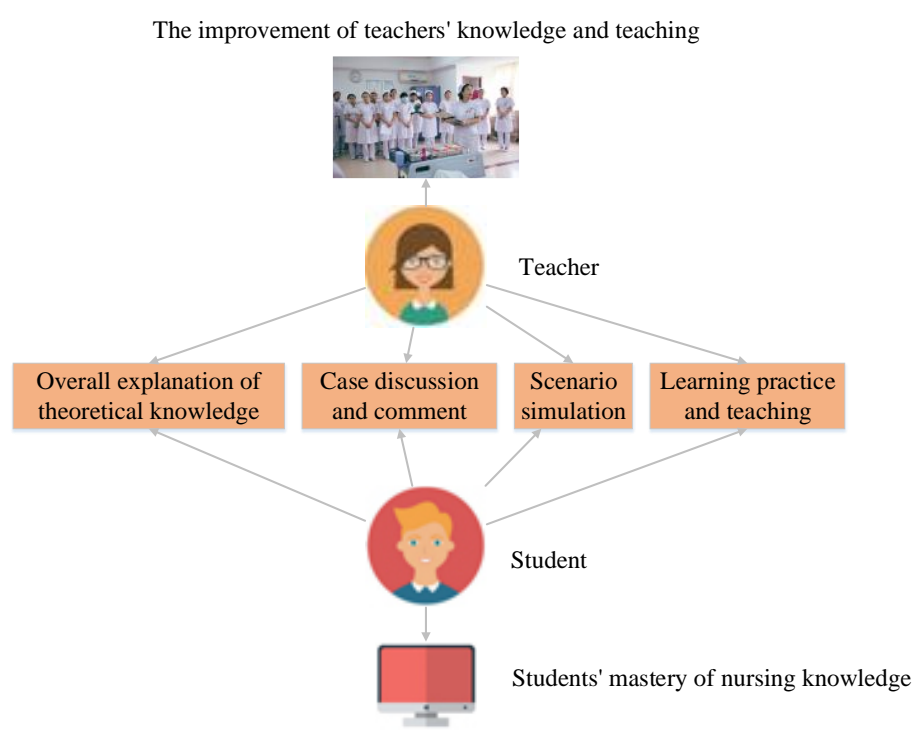

Fig. 3. Diagram of nursing course teaching model based on UCD 


\subsection{Development of evaluation system of Fundamental Nursing course based on objective-process structure relation}

Index weight is a key problem for constructing the evaluation index system. At present, general methods to determine index weight include subjective weighting, objective weighting and the combination of the two.

First of all, grey correlation method and fuzzy thought can be used to construct an index system and gain the index set. Next, relevant persons may be consulted and invited to score the indexes, and analytic hierarchy process is applied to calculate the weight of each index. In this way, a complete index system is preliminary established. Next, the design and determination of index weight are analyzed simply as below:

The index set is established according to the evaluation index system, expressed as

$\mathrm{I} 1=[\mathrm{I} 11]$

$\mathrm{I} 2=[\mathrm{I} 21, \mathrm{I} 22, \mathrm{I} 23, \mathrm{I} 24]$

$\mathrm{I} 3=[\mathrm{I} 31, \mathrm{I} 32, \mathrm{I} 33]$

$\mathrm{I} 4=[\mathrm{I} 41, \mathrm{I} 42, \mathrm{I} 43]$

Primary index weight is calculated according to analytical hierarchy process, and confirmed by experts. With regard to the selection of experts, course teacher, students, department head and teaching manager can be chosen. Through repeated consultation, expert opinions are handled to gain matrix X:

$$
X=\left[\begin{array}{cccc}
1 & 5 & 2 & 5 \\
1 / 5 & 1 & 1 & 2 \\
1 / 2 & 1 & 1 & 2 \\
1 / 5 & 1 / 2 & 1 / 2 & 1
\end{array}\right]
$$

The judgment matrix is normalized. Through the calculation, the weights of primary indexes are gained: .35, 0.30, 0.20, 0.15 .

The coincidence index ${ }^{C_{i}}$ of analytic hierarchy process is defined as:

$$
C_{i}=\frac{\lambda_{\max }-n}{n-1}
$$

Wherein, $n$ is the order of the judgment matrix; $\lambda_{\max }$ refers to the maximum eigenvalue of the judgment matrix.

Based on the above matrix, calculate $\lambda_{\max }=5.723>5$

Compute the coincidence index of the matrix, $C_{i}=\frac{\lambda_{\max }-n}{n-1}=0.063$

Table 1. Values of mean random consistency index (RI) for 1-9-order matrixes

\begin{tabular}{|c|c|c|c|c|c|c|c|c|c|}
\hline & $\mathbf{1}$ & $\mathbf{2}$ & $\mathbf{3}$ & $\mathbf{4}$ & $\mathbf{5}$ & $\mathbf{6}$ & $\mathbf{7}$ & $\mathbf{8}$ & $\mathbf{9}$ \\
\hline $\mathrm{RI}$ & 0.00 & 0.00 & 0.52 & 0.89 & 1.12 & 1.26 & 1.36 & 1.41 & 1.46 \\
\hline
\end{tabular}


According to the table 1, mean random consistency index of 4-order matrix $\mathrm{RI}=0.89$. In this way, consistency ratio of the matrix can be figured out, $C_{R}=\frac{C_{i}}{R I}=\frac{0.063}{0.89}=0.071<0.1$ - According to the test, the judgment matrix meets consistency. Similarly, calculate the secondary index weight.

Table 2 shows the evaluation index system of course quality I, and there are 4 $(\mathrm{x}=4)$ primary indexes, $11(\mathrm{y}=11)$ secondary indexes and $18(\mathrm{z}=18)$ third-level indexes. Each index at the same level has different degree of importance for course quality. The weight calculation results of indexes at all levels are shown in Table 2.

Taking course quality I as the objective layer and third-level indexes as the scheme layer, further figure out the total priority weight of the index set of scheme layer relative to the objective layer. Table 3 displays the total weight results of third-level index set relative to the objective layer of course quality I. The total priority weight vector of third-level index set relative to the objective layer of course quality I can be expressed as: $W=\left(w_{1}, w_{2}, \Lambda, w_{m}\right)^{T},(m=18)$

Table 2. Evaluation index system of course quality (I)

\begin{tabular}{|c|c|c|c|c|c|}
\hline \multicolumn{2}{|c|}{$\begin{array}{c}\text { Primary index and } \\
\text { weight }\end{array}$} & \multicolumn{2}{|c|}{ Secondary index and weight } & \multicolumn{2}{|c|}{ Third-level index, unit and weight } \\
\hline $\operatorname{Ix}(x=1, \ldots, a)$ & $W_{x}^{(1)}$ & $\operatorname{Ixy}(y=1, \ldots, b x)$ & $W_{x y}^{(2)}$ & $\operatorname{Ixyz}(z=1, \ldots, \mathrm{cxy})$ & $W_{x y z}^{(3)}$ \\
\hline $\begin{array}{l}\text { I1 Course } \\
\text { objective } \\
\text { adaptation }\end{array}$ & 0.35 & $\begin{array}{l}\text { I11 Degree of course } \\
\text { objective adapting to } \\
\text { major graduation } \\
\text { requirements }\end{array}$ & 1 & $\begin{array}{l}1111 \text { Support of course objective } \\
\text { for achieving major graduation } \\
\text { requirements }\end{array}$ & 1 \\
\hline \multirow{7}{*}{$\begin{array}{l}\text { I2 Teaching } \\
\text { resource } \\
\text { guarantee }\end{array}$} & \multirow{7}{*}{0.30} & \multirow{2}{*}{$\begin{array}{l}\text { I21 Degree of teaching } \\
\text { resource level meeting } \\
\text { teaching demand }\end{array}$} & \multirow[t]{2}{*}{0.45} & $\begin{array}{l}\text { I211 Correlation of teacher's } \\
\text { education background, teaching, } \\
\text { scientific research and work } \\
\text { experience with the course }\end{array}$ & 0.65 \\
\hline & & & & $\begin{array}{l}\text { I212 Degree of applying } \\
\text { multimedia platform to serve } \\
\text { course teaching }\end{array}$ & 0.35 \\
\hline & & \multirow{2}{*}{$\begin{array}{l}\text { I22 Applicability of } \\
\text { course teaching material }\end{array}$} & \multirow{2}{*}{0.21} & $\begin{array}{l}\text { I221 Correlation of textbook } \\
\text { content with knowledge, ability } \\
\text { and quality requirements }\end{array}$ & 0.25 \\
\hline & & & & $\begin{array}{l}\text { I222 Contribution degree of } \\
\text { existing teaching and scientific } \\
\text { research achievements }\end{array}$ & 0.75 \\
\hline & & \multirow{2}{*}{$\begin{array}{l}\text { I23 Completeness of } \\
\text { teaching equipment }\end{array}$} & \multirow[b]{2}{*}{0.19} & $\begin{array}{l}\text { I231 Degree of teaching } \\
\text { equipment meeting teaching needs } \\
\text { in terms of quantity }\end{array}$ & 0.60 \\
\hline & & & & $\begin{array}{l}\text { I231 Degree of teaching } \\
\text { equipment meeting teaching needs } \\
\text { in terms of function and } \\
\text { performance }\end{array}$ & 0.40 \\
\hline & & $\begin{array}{l}\text { I24 Sufficiency of course } \\
\text { fund input }\end{array}$ & 0.15 & $\begin{array}{l}\text { I241 Degree of course funds } \\
\text { meeting teaching demand }\end{array}$ & 1 \\
\hline $\begin{array}{l}\text { I3 Teaching } \\
\text { program } \\
\text { execution }\end{array}$ & 0.20 & $\begin{array}{l}\text { I31 Rationality of course } \\
\text { teaching program }\end{array}$ & 0.40 & $\begin{array}{l}\text { I311 Adaptation degree of } \\
\text { teaching methods to students' } \\
\text { knowledge mastery, ability and }\end{array}$ & 0.60 \\
\hline
\end{tabular}




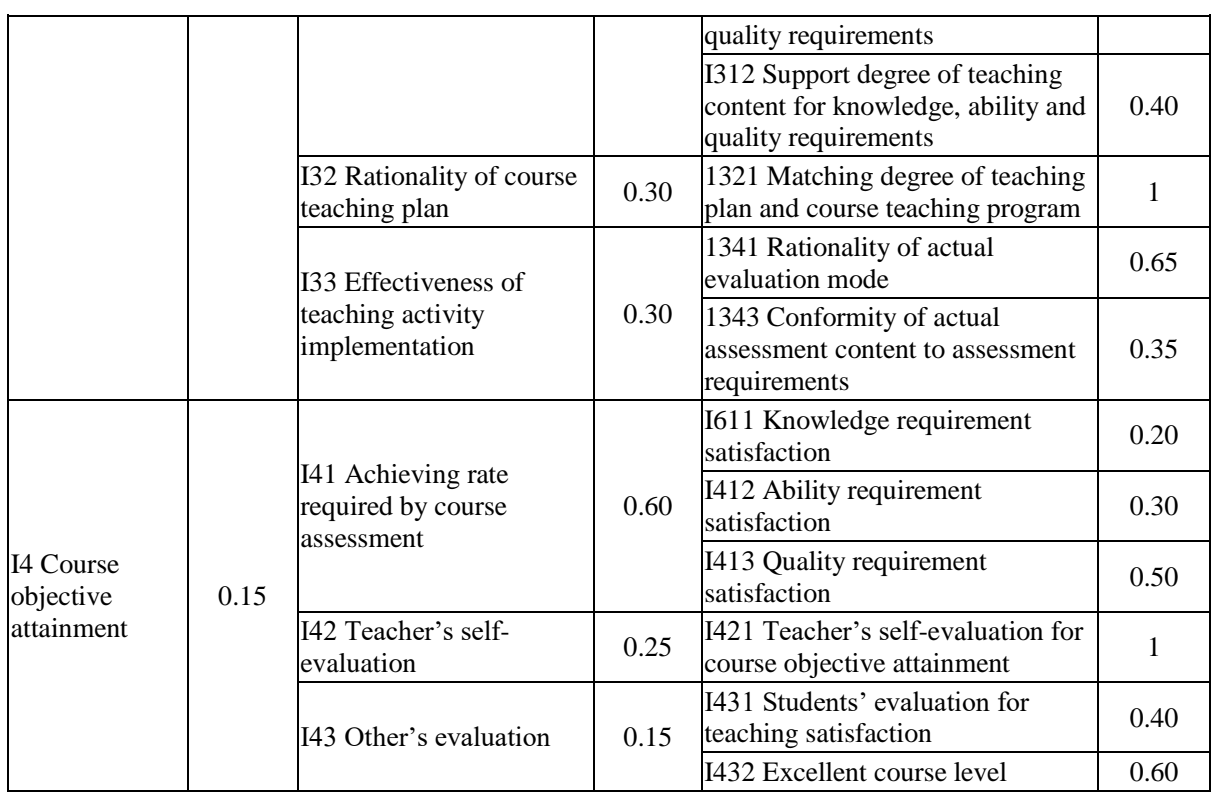

Table 3. Total priority weight of the index set of scheme layer relative to the objective layer

\begin{tabular}{|c|c|c|c|c|c|}
\hline Index & Weight & Index & Weight & Index & Weight \\
\hline I111 & 0.35 & I241 & 0.045 & I611 & 0.018 \\
\hline I211 & 0.0878 & I311 & 0.048 & I612 & 0.027 \\
\hline I212 & 0.0473 & I312 & 0.032 & I613 & 0.045 \\
\hline I221 & 0.0158 & I321 & 0.06 & I621 & 0.0375 \\
\hline I222 & 0.0473 & I341 & 0.039 & I631 & 0.009 \\
\hline I231 & 0.0228 & I343 & 0.021 & I632 & 0.0135 \\
\hline
\end{tabular}

P1, P2 and P3 represent three main courses of nursing major: Fundamental Nursing, Medical Nursing, and Surgical Nursing, which are used to analyze course quality in 2019. The index data of each course are gained mainly through the following ways: the course teacher provides the data according to the specific conditions in the teaching process; the Surgical Nursing and the office of academic affairs of the college assist in providing relevant data.

The relationship among course quality evaluation indexes is not very clear, with the characteristics of "gray" information. Thus, gray correlation analysis method can be used to process the original data of course quality third-level indexes to gain the correlation coefficient matrix:

$$
F=\left(\xi_{0 l}\left(I_{x y z}\right)\right) n x m=\left[\begin{array}{cccc}
\xi_{01}(1) & \xi_{01}(2) & \Lambda & \xi_{01}(m) \\
\xi_{02}(1) & \xi_{02}(2) & \Lambda & \xi_{02}(m) \\
M & M & M & M \\
\xi_{0 n}(1) & \xi_{0 n}(2) & \Lambda & \xi_{0 n}(m)
\end{array}\right],(n=3, m=18)
$$


Wherein, $\mathrm{n}$ is the number of courses evaluated; $l$ is the serial number of objects participating in the evaluation; $\xi_{0 l}(I x y z)$ refers to the correlation coefficient of the lth object participating in the evaluation on the attribute of the Ixyzth index. This study gives the data processing results of the third-level index "degree of teaching resource level meeting teaching demand" $I 21 Z(Z=1,2)$ in 2019 , namely, the calculation results of correlation coefficient matrix F21Z, as shown in Table 4. The data processing of other third-level indexes is omitted here.

Table 4. Data of correlation coefficient matrix F21Z of $I 21 Z$ in $2019(Z=1,2)$

\begin{tabular}{|c|c|c|c|}
\hline Index - Course & P1 & P2 & P3 \\
\hline I 211 & 0.613 & 0.854 & 0.623 \\
\hline I212 & 0.832 & 0.924 & 0.662 \\
\hline
\end{tabular}

\section{Teaching Example and Effect}

\subsection{Teaching example}

The era of "internet +" education has come, and a new opportunity appears to the change of teaching models. Under such context, this study introduced UCD theory, and combined all kinds of high-quality course resources such as excellent course teaching plan, electronic courseware, teaching video, micro lesson video, question bank, and extended resources to construct a four-in-one (blended-flippedautonomous-collaborative) teaching model with the help of a triune (Mooc, WeChat official platform and world university town) online teaching platform. This study aims to provide theoretical reference for cultivating high-quality nursing personnel with strong autonomous learning ability, collaboration ability and information literacy, provide the reference for teaching model reform of other medial courses and provides the early exploration for colleges to promote information-based education reform. This study created the micro-course of Fundamental Nursing, and established a triune (Mooc, WeChat official platform and world university town) online teaching platform. Based on the empirical study of core courses of nursing major, this study evaluated the application effect of four-in-one teaching model under the background of internet + . Next, Fundamental Nursing is taken for example to explore the application and effect of four-in-one teaching model based on UCD theory in the nursing course, and to give the teaching effect evaluation. Fig.4 shows the four-in-one teaching model based on UCD theory, and Fig.5 displays the application step of this model in Fundamental Nursing. 


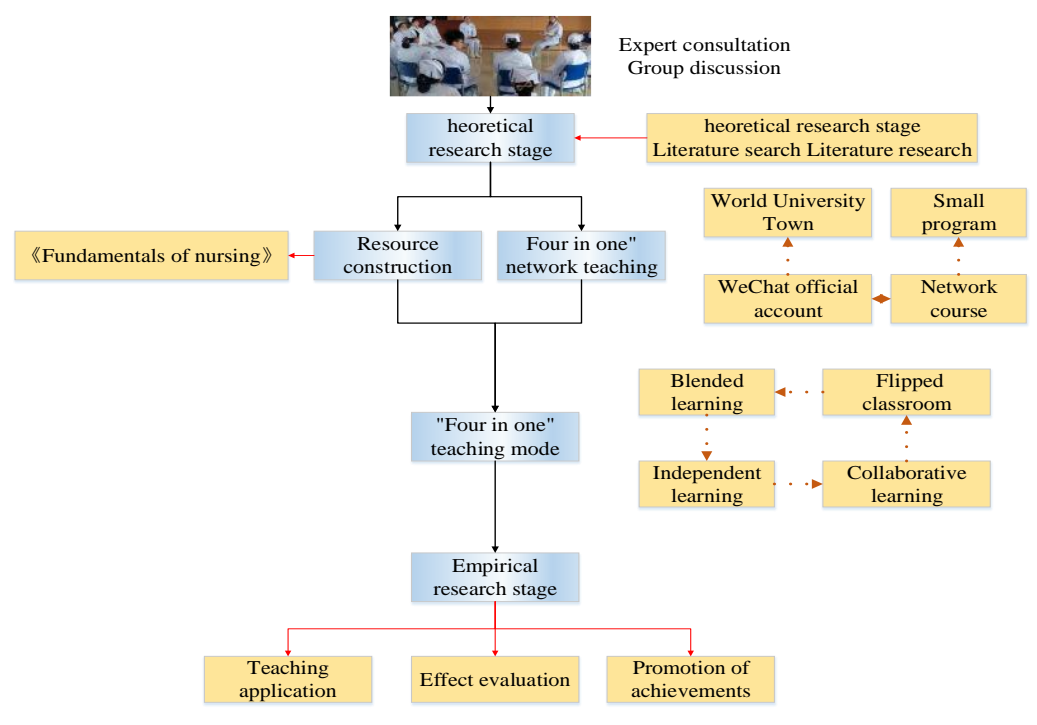

Fig. 4. Four-in-one teaching model based on UCD theory

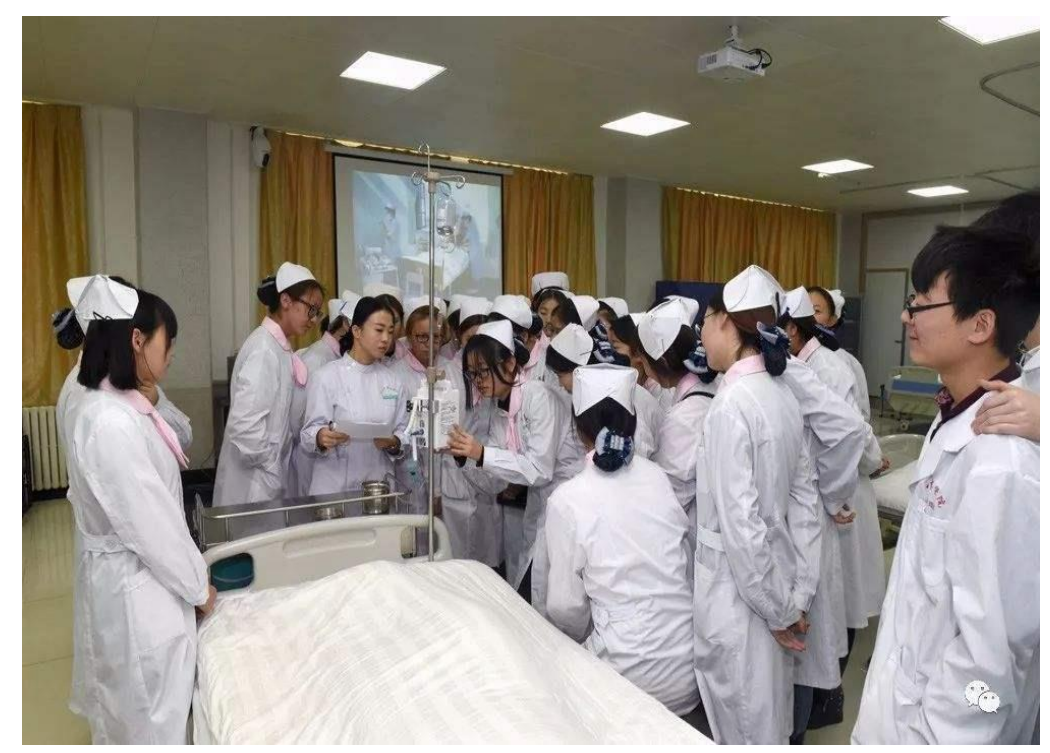




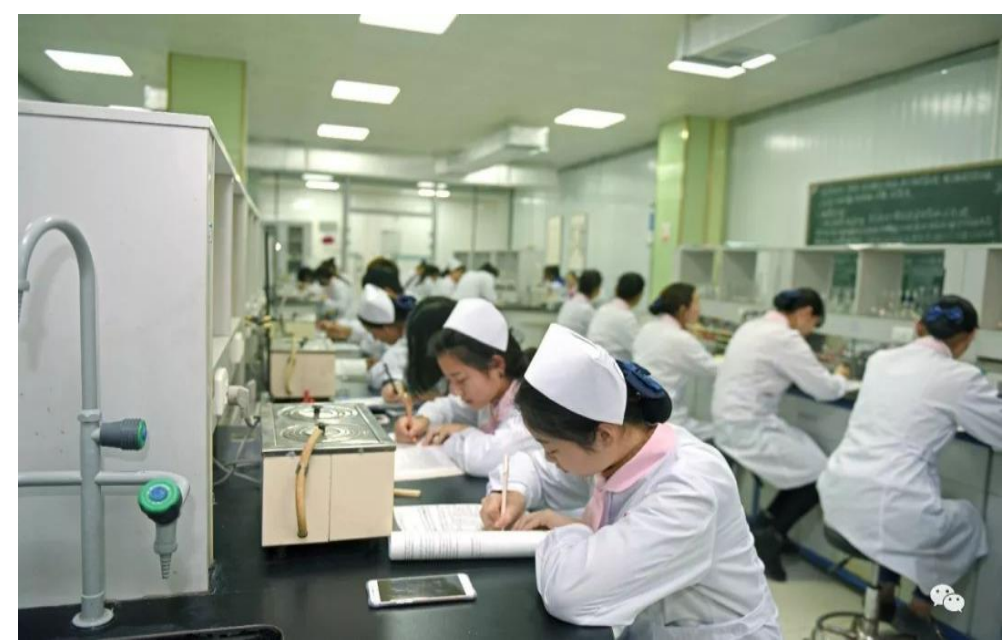

Fig. 5. Application scene of four-in-one teaching model based on UCD theory in nursing teaching

\subsection{Teaching effect}

The cluster sampling method was used to choose 209 nursing students from a local university who were enrolled in 2016 as the objects of study, and Class 1 and Class 2 were drawn at random as the experimental group, while Class 3 and Class 4 were the control group. There were 104 students in the experimental group, including 87 female students and 17 male students, with the age of 17-22 years old an average age of (19.80-10.83) years old. There were 105 students in the control group, including 94 female students and 11 male students. The comparison differences between two groups in general data and academic results were not significant $(\mathrm{P}>0.05)$. The teaching materials and teacher were same for both groups. All students were informed of this study and agreed, and they were willing to participate in this study. The control group was adopted to evaluate the effect of four-in-one teaching model based on UCD theory on Fundamental Nursing. A traditional teaching method was applied for the control group, that is, the teacher explained knowledge points and students listened to the teacher. The four-in-one teaching model was adopted for the experimental group, mainly involving teamwork, problem solving and case analysis.

SE-PETE questionnaire designed by MartinE•Block team was employed to investigate students' satisfaction for the four-in-one teaching model and the traditional teaching method. The scale includes four indexes: knowledge mastery satisfaction, classroom performance, classroom pleasure degree and self-efficacy. Each index was scored by five levels (100/70/40/10/0 marks). The mark of each question was converted into the mean mark of each index. 236 questionnaires were distributed, and 220 were recovered, including 198 effective questionnaires, with the effective recovery rate of $84 \%$. 
Table 5. Score comparison of autonomous learning ability in both groups

\begin{tabular}{|l|c|c|c|c|}
\hline \multicolumn{1}{|c|}{ Group } & $\begin{array}{c}\text { Self-management } \\
\text { ability }\end{array}$ & $\begin{array}{c}\text { Information } \\
\text { acquisition ability }\end{array}$ & $\begin{array}{c}\text { Learning and } \\
\text { cooperation ability }\end{array}$ & $\begin{array}{c}\text { Total } \\
\text { score }\end{array}$ \\
\hline Control group & 71.89 & 75.12 & 74.82 & 70.25 \\
\hline Experimental group & 76.45 & 79.75 & 81.72 & 79.25 \\
\hline
\end{tabular}

\section{Conclusion}

Nursing course teaching is confronted with the situations of low learning initiative and imperfect teaching evaluation system. To solve the above problems, this study proposed a four-in-one teaching model based on UCD theory, and designed a course quality evaluation index system to assess the teaching effect of this model. The main conclusions and future expectations are as below:

This study introduced a four-in-one teaching model based on UCD theory. Through the comparative study with other traditional teaching methods, it is found that the four-in-one teaching model is better than traditional teaching methods in terms of students' self-management ability, information acquisition ability, learning and cooperation ability, and total score.

This study constructed a course quality evaluation index system. Starting from the objective of training program of nursing major, the teaching effect of nursing major courses was quantified from multiple dimensions. This study aims to offer an evaluation scheme for cultivating innovative students and guiding the teaching effect of nursing major courses.

The defects of this study are that only students' autonomous learning ability was compared in teaching effect evaluation, and the proposed teaching model was scored only from students' perspective. Besides, the data are not comprehensive enough. Both teachers and colleges should be taken into account.

\section{Acknowledgement}

"Thirteenth Five-Year Plan" of Educational Science in Hunan Province (XJK17CGD042), Higher Education and Teaching Reform Project of Hunan Province (2019-884) and Higher Education and Teaching Reform Project of Hunan Province (2018-716) supported this work.

\section{$7 \quad$ References}

[1] Abdullah, M.K., Ibrahim, R.H., \& Abdulla, R.K. Nursing students' attitudes toward simulation technology in nursing education. International Journal of Emerging Technologies in Learning, 2019, vol. 14(14), pp. 31-45. https://doi.org/10.3991/ijet.v14i14. 10571

[2] Alhosban, F., \& Ismaile, S. Perceived promoters of and barriers to use of a learning management system in an undergraduate nursing program. International Journal of 
Emerging Technologies in Learning, 2018, vol. 13(2), pp. 226-233. https://doi.org/10.399 1/ijet.v13i02.8085

[3] Nikhilesh, S., Richa, G., \& Mahalakshmi, V.N. Multistation exercises: a combination of problem-based learning and team-based learning instructional design for large-enrollment classes. Advances in Physiology Education, 2018, vol. 42(3), pp. 424-428. https://doi.org/ 10.1152/advan.00023.2018

[4] Baran, M., Sozbilir, M. An Application of Context- and Problem-Based Learning (C-PBL) into Teaching Thermodynamics. Research in Science Education, 2018, vol. 48(4), pp. 663689. https://doi.org/10.1007/s11165-016-9583-1

[5] Maas, J.A., Toonkel, R.L., Athauda, G. Large Group Case-Based Learning (TB-CBL) Is an Effective Method for Teaching Cancer Chemotherapy to Medical Students. Medical Science Educator, 2018, vol. 28(1), pp. 191-194. https://doi.org/10.1007/s40670-018-053 $\underline{7-2}$

[6] Feng, W.W. Multi-objective optimization algorithm for multimedia english teaching (moamet) based on computer network traffic prediction model. International Journal of Emerging Technologies in Learning, 2018, vol. 13(3), pp. 58-70. https://doi.org/10.3991/ij et.v13i03.8372

[7] Li, K.C., Lee, L.Y.K., Wong, S.L., et al. Mobile learning in nursing education: catering for students and teachers' needs. Asian Association of Open Universities Journal, 2017, vol. 12(2), pp. 171-183. https://doi.org/10.1108/aaouj-04-2017-0027

[8] Wang, S.T. Application of situational problem-based learning in bilingual nursing teaching. China Journal of Modern Medicine, 2018, vol. 28(30), pp. 127-128.

[9] Wu, L.X., Zhao, B., Zhu, Z.P. The Study and Practice of Procedure Teaching Method in College Non-P. E. Major. Sichuan Sports Science, 2005, vol. 16(4), pp. 138-139.

[10] Xie, S.X., Yang, Q.P., Chen, Y.C., Liu, G. Construction and application of synchronous flipped classroom teaching mode in multi campus. Higher education exploration, 2018, vol. 37(9), pp. 37-43.

[11] Xu, C.S., Lu, Y., Song, F.Y., et al. Improving the teaching of "thermal experiment" and strengthening the cultivation of independent experimental ability. Laboratory science, 2016, vol. 19(2), pp. 148-151.

\section{Authors}

Pan Li is an associate professor in the School of Nursing, Xiangnan University, Chenzhou, China (pp18075531160@163.com).

Chunyan Li (Correspondence Author) is a professor in the School of Nursing, Xiangnan University, Chenzhou, China (pp18075531160@163.com).

Article submitted 2020-05-23. Resubmitted 2020-06-27. Final acceptance 2020-06-28. Final version published as submitted by the authors. 